\title{
New feed additive method for improving cow health
}

\begin{abstract}
Mastitis is a common and expensive disease affecting approximately one-third of dairy cattle in the world. While there are several causes for mastitis, the major cause is bacterial infection. It is treatable primarily with antibiotics, but nutritional remedies also exist such as Vitamin D supplementation. When Vitamin D supplementation is used in tandem with BOOSTER technology, mastitis could be cured using a lesser quantity of the vitamin and be far more effective. BOOSTER technology also seems to boost immunity, preventing the recurrence of this disease. We believe that this type of application will allow farmers to increase milk production, eliminate use of antibiotics for mastitis and increase overall herd health by decreasing diarrhea.1,2 It is expected that there will be no additional cost for implementation of this system due to the offset of care and material costs borne by dealing with current health issues and treatments.
\end{abstract}

Volume I Issue 3 - 2014

\section{Leonard Sonnenschein}

World Aquarium and Conservation for the Oceans Foundation, USA

Correspondence: Leonard Sonnenschein, President, World Aquarium, 70I North I5th Street, 2nd Floor, St. Louis, MO 63103, USA, Tel 314647 60II, Fax 314647 7874, Email LSAQUAMAN@aol.com

Received: August 3I, 20I4 | Published: December 31, 2014

Keywords: cow, health, mastitis, diarrhea, feed additives, health, immunity

\section{Introduction}

Mastitis is a common and expensive disease affecting approximately one-third of dairy cattle in the world. Costing approximately $\$ 200$ per cow per year, dairy producers lose money through reduced milk production, replacement costs, milk thrown away, cow treatments, and veterinary expenses. Mastitis is an inflammation in the mammary glands which can be the result of bacterial, chemical, thermal or mechanical sources. It can be either communicable or noncommunicable, depending upon how it is contracted. Mastitis can be caused by microorganisms, bacteria, yeasts, mycoplasmas and algae, but most infections are caused by bacteria.

Mastitis is mostly caused by contagious bacteria that are spread from an infected udder to other cows, or by bacteria that are in the cow's environment and enter through the teats. Mastitis infections may be clinical or subclinical. Clinical mastitis is evident through visible abnormalities in the udder or in the milk. Subclinical mastitis can only be identified by testing cells to detect microorganisms.

There are several cures for mastitis: antibiotics, mammary infusions, and sanitation. Antibiotics and mammary infusions require disuse of milk from infected cows, which can be very costly. Sanitation practices are great for prevention purposes. Natural cures are not main stream. The USDA has confirmed that supplementation of Vitamin $\mathrm{D}$ has been found to be a natural curative for mastitis. They found a significant reduction in signs of severe infection in cows treated with vitamin $\mathrm{D}$, compared to cows that received no treatment. As bacterial counts decreased, milk production increased in treated animals. Supplementation with Vitamin D also may reduce occurrence of other bacterial and viral diseases, such as respiratory tract infections.

"Understanding Cellular Metabolism: Nutrition, Health, and Beauty"3 was recently published showing the biochemical relationships for application to human and animal health as well as for agricultural applications. For aquaculture applications (Gro Fish), significant growth was found in over 30 species of fish and invertebrates such as salmon, tilapia, shrimp and corals. In addition to growth, simple one-time cellular treatments were found to affect the immune systems of shrimp, greatly improving their resistance to deadly viruses such as white spot disease and bacterial threats.
Currently, this application of nutritional science coupled with cellular and physiologic responses are postulated for being applied to cow health. ${ }^{4}$ This new feed additive can be tested for decreasing mastitis ${ }^{5-7}$ and diarrhea as well as improving milk production that is based on the nature of the ruminant system ${ }^{8-11}$ for natural vitamin production through mineral supplements and other organic materials. We have found by reviewing various diets Chiba $\mathrm{L}^{11}$ certain deficiencies that can be addressed Rounds W \& Dennis BH, ${ }^{12}$ Williams CC,,${ }^{13}$ ARS: News \& Events ${ }^{14}$ in conjunction with the Agricultural University of Sweden in Uppsala, we are ready to study these applications and will shortly report the outcomes. Our current research has identified a new mechanism for understanding cell metabolism, which is controlled by the cell membrane. ${ }^{3}$ BOOSTERTM, a patent-pending process utilizing this mechanism, enhances the uptake of active ingredients in pharmaceutical, nutraceuticals, and cosmetic markets.

Recent patent-pending understanding of how to improve the delivery of active ingredients (Sonnenschein, Leonard, Methods and compositions for enhancing the uptake of an active ingredient, US Provisional Application \#61/716331, filed October 17, 2012) is expected to have profound effects on the medical, pharmaceutical, nutritional, cosmetic, and homeopathic industries. This metabolic process has opened up a new territory of cellular metabolism by identifying the cell membrane as the controller rather than the nucleus ("New Mechanisms to Understanding the Cell Membrane's Role in Modulating Intercellular Metabolism for Nutritional Delivery," Swedish University of Agricultural Sciences). The capacity of the cell membrane for transfer of essential nutrition can be enhanced even to the novel delivery of large molecules that may further benefit cellular metabolism as demonstrated by Leonard Sonnenschein ${ }^{3}$ in his patent from 2001 (Sonnenschein, Leonard, Method of stimulating growth in aquatic animals, US Patent 6,238,706, issued May 29, 2001), which shows the ability to move large protein synthesis stimulator molecules into the cell.

\section{Materials and methods}

Independent laboratory analysis (GVK, Hyderabad, India) of the efficacy of BOOSTERTM has been conducted. Male mice were administered vitamin $\mathrm{D}_{3}$ along with a control or a BOOSTERTM- 
supplemented diet. The objective of this study was to determine the urine concentrations of vitamin $\mathrm{D}_{3}$ in mice after oral administration of vitamin $\mathrm{D}_{3}$ incorporated in the diet at 25,000 International Units.

\section{Results}

The BOOSTERTM-treated urine concentration of vitamin $\mathrm{D}_{3}$ was 9.8times higher than the control group (Figure 1). Therefore,
BOOSTER $^{\mathrm{TM}}$ very significantly increased the absorption of vitamin $\mathrm{D}_{3}$ in this mammalian model.

Male mice were administered Vitamin $\mathrm{D}_{3}$ (25000 International Units) along with control or BOOSTERTM supplemented diet. Source: Animal Facility and Bioanalytical and Pharmacokinetic Analysis Facility, GVK Biosciences Private Limited. Biology Division, 28A, IDA, Nacharam, Hyderabad, 500 079, India.

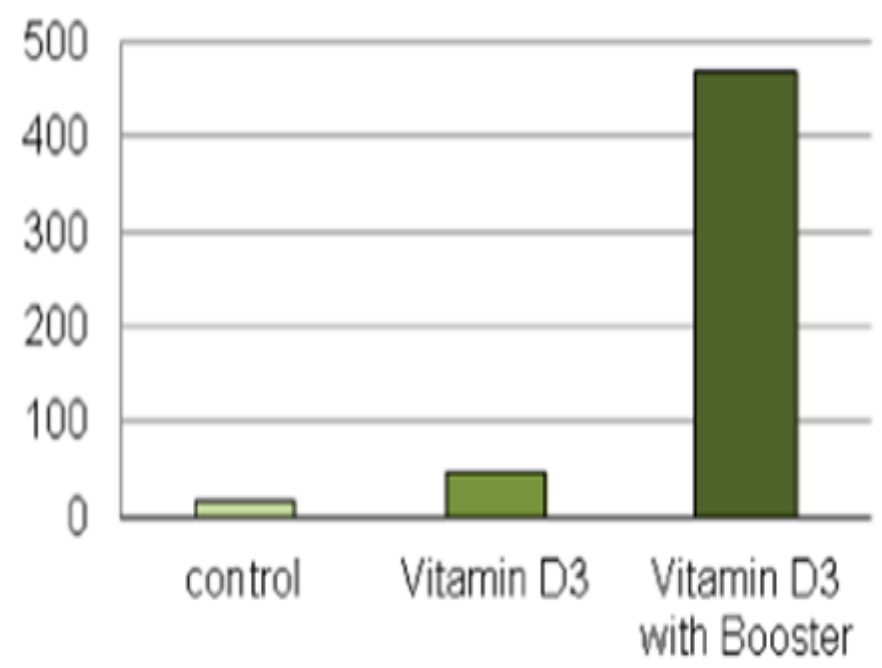

Figure I Graphical representation of BOOSTERTM-treated urine concentration of vitamin $\mathrm{D}_{3}$.

\section{Discussion}

BOOSTER $^{\mathrm{TM}}$ works through utilization of a transport effect as solution changes by molecular proportions. This is a transport affected by solution changes. Larger pore/channel openings allow a subsequent larger molecule passage and/or cellular incorporation depending on molecule concentration of the solution and its constitution. Figures $2 \& 3$ shows how BOOSTER works through facilitating the movement of an active ingredient through the cell wall.

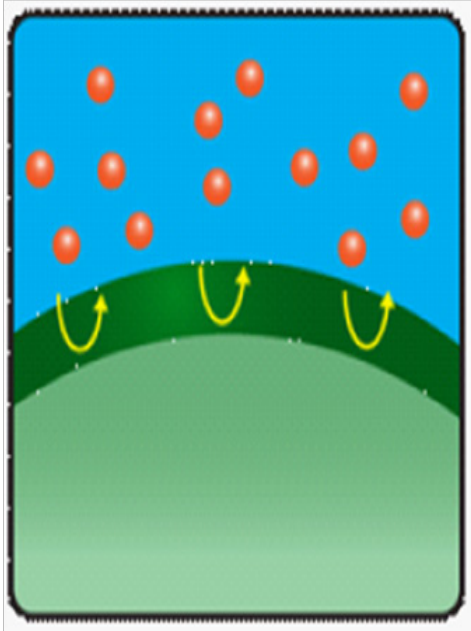

\section{No BOOSTER ${ }^{\text {TM }}$}

Without BOOSTER ${ }^{\mathrm{TM}}$, the cell retains its normal hydration and physical properties of resistance including osmotic regulation and only water and small, water-soluble molecules such as sodium, glucose, potassium, and other ions can transport through the cell membrane. This newly identified active-ingredient delivery system will allow for using less raw product in formulations with a more efficient delivery, a significantly decreased price, increased potency, and potentially reduced side effects, thereby creating a new model for improving the cattle health condition.

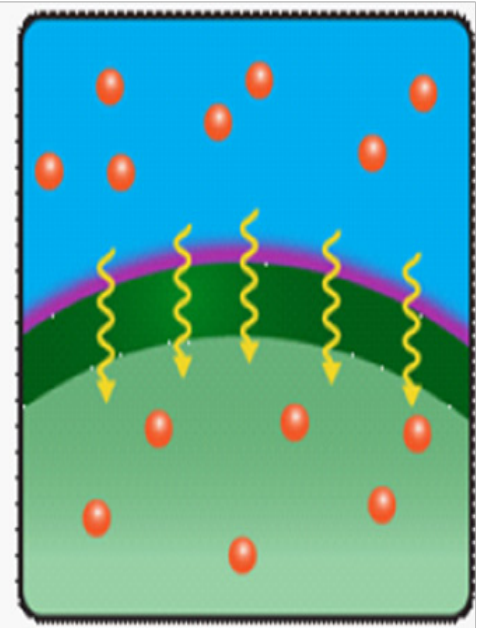

With BOOSTER ${ }^{\text {TM }}$

Figure 2 Active ingredients moving through a cell wall. 

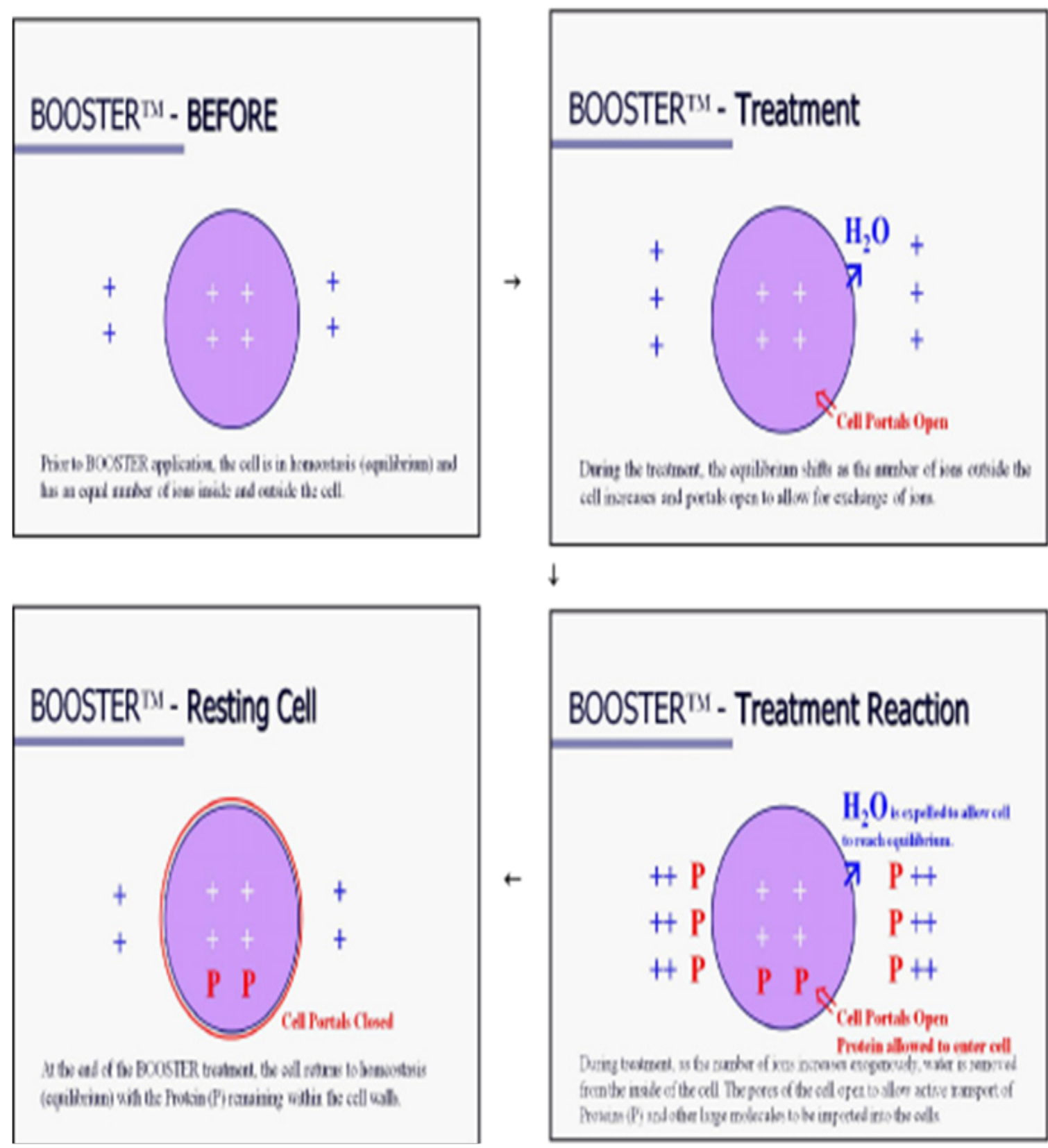

Figure 3 The booster cellular process.

\section{Conclusion}

We are only at the beginning of understanding of the applications for agricultural uses for BOOSTER. Due to the complex nature of rumen function for cattle it may be possible to use BOOSTER technology in the animal feed to further improve uptake of nutrients as well as to stimulate health at the cellular level from feed additives. With recent changes regarding antibiotic use in the livestock industry, there is an increasing need to find organic solutions to improving health and productivity. We believe that BOOSTER technology will allow farmers to increase milk production, eliminate use of antibiotics for mastitis and increase overall herd health by decreasing diarrhea. ${ }^{1,2}$ It is expected that there will be no additional cost for implementation of this system due to the offset of care and material costs borne by

\section{BOOSTERDI - Treatment Reaction}

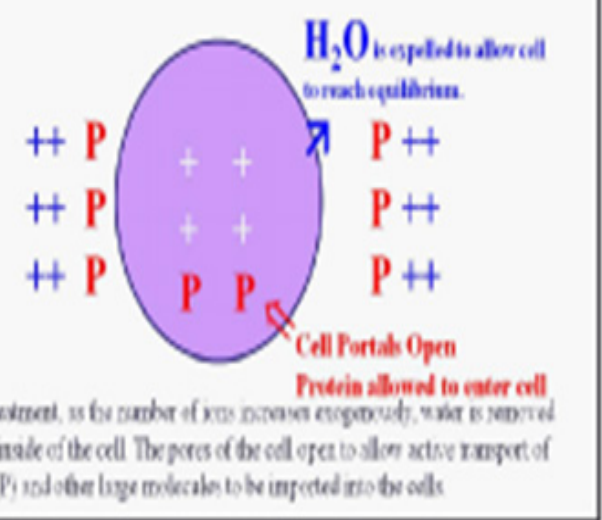

dealing with current health issues and treatments.

\section{Acknowledgements}

The author would like to acknowledge the World Aquarium Staff in supporting the bench-level research through animal care and husbandry for research systems as well as over three hundred interns who have come to the World Aquarium since 1992 to engage in applied-science research projects that expanded knowledge of sustainable aquaculture, sustainable agriculture, coral reef ecology, eutrophic zone chemistry, and climate change adaptation.

\section{Conflict of interest}

Author declares that there is no conflict of interest. 


\section{References}

1. Wells SJ, Ott SL, Seitzinger AH. Key Health Issues for Dairy CattleNew and Old. J Dairy Sci. 1998;81(11):3029-3035.

2. Taylor RF. A Case Study on a Dairy With Herd-wide Diarrhea and Reduced Milk Production. California Polytechnic State University. 2013.

3. Sonnenschein L. Understanding Cellular Metabolism: Nutrition, health and beauty. Charleston: Create Space Independent Publishing Platform; 2013.

4. Beauchemin Karen, Greg Penner. New Developments in Understanding Ruminal Acidosis in Dairy Cows. eXtension. 2011.

5. Mueller FJ, Miller JK, Campbell MH, et al. Prevention of Udder Edema in Dairy Cows. eXtension. 2012.

6. Schroeder JW. Bovine Mastitis and Milking Management. North Dakota State University. 2013.

7. Weiss WP. Minerals and Vitamins for Dairy Cows: Magic Bullets or Just Bullets? Department of Animal Sciences, Ohio Agricultural Research and Development Center. 2013
8. Virginia Ishler. From Feed to Milk: Understanding Rumen Function. Dairy Cattle Nutrition (Penn State Extension). 2013.

9. David Lalman, Casey McMurphy. Vitamin and Mineral Nutrition of Grazing Cattle. Oklahoma State University. 2013:E861.1-E861.13.

10. Borah S, Babul CS. Micronutrient in Sustainable Animal Production. 2013.

11. Chiba L. ANIMAL NUTRITION Handbook. 2014.

12. Rounds W, Dennis BH. The Cow's Digestive System. Texas Agricultural Extension Service. 2014.

13. Williams CC, Gerald AS. Mastitis in Dairy Cattle. LSU Agricultural Center. 2009;52(1):21.

14. Strategies That Work Alternatives to Antibiotics in Animal Health. ARS: News \& Events US. Department of Agriculture. 2012;60(5):4-7. 